MATEC Web of Conferences 22,02019 (2015)

DOI: $10.1051 /$ matec conf/ 20152202019

(C) Owned by the authors, published by EDP Sciences, 2015

\title{
Review on the Distributed Energy Storage Technology in the Applica- tion of the Micro Network
}

\author{
Qiyuan Huang, Zhijie Wang*, Jun Zhu, Dongwei Wang, Bin Du \\ College of Electrical Engineering, Shanghai Dianji University, Shanghai, China
}

\begin{abstract}
This paper summarized the application process of energy storage technology in the micro-grid, elaborated on the development of energy storage technology concisely, and illustrated the roles of battery energy storage, flywheel energy storage, superconducting magnetic energy storage (SMES), super capacitor energy storage and other energy storage and so on in micro-hybrid. Then it compared the performances of some sorts of the storage method. As characteristics and actual demands of micro-grid work were given full into consideration, the current micro-grid energy storage technology research problems and development trend in the future were pointed out.
\end{abstract}

Keywords: energy storage technology; micro-grid; SMES; hybrid energy storage

\section{INTRODUCTION}

Smart micro-grid technology is one of the hot spots of current research; it has the characteristics of flexible operation and high new energy efficiency. But due to the intermittent and volatility of wind power or solar power supply of micro-grid, it will greatly affect the quality of power supply of power grid. And energy storage technology can well restrain power fluctuations, smooth the output power of micro-grid, and substantially increase power quality, stability and power supply reliability of power grid. It is a small investment in energy-saving measure to effectively use clean energy. Therefore, this article paid attention to analyzing the energy storage technology for micro network research.

\section{FUNCTION OF ENERGY STORAGE IN THE MICRO-GRID}

The application of energy storage technology in micro-grid is shown in Figure 1.

\subsection{Adjust the peak of the power system parameters}

Because micro power grid makes use of distributed power supply, it cannot remain the total load unchanged forever and weather changes can also cause the wave. In addition, regular micro-grid is a smaller system, its poor self-adjusting ability and power grid and load fluctuation will seriously affect the stable operation of the micro-grid. In order to adjust the system peak load, peaking power plants must be used. But at this stage, the main operation of peaking power plant is expensive and difficult to achieve. The energy storage system can effectively solve this problem, when the load declines, it can be used to store excess energy, while feedback energy to the micro power grid to adjust power when the load peak comes. As a micro-grid energy buffer link, the effect of energy storage system is more and more important. It not only makes full use of the power of the generator set in low ebb, but also avoids installing generator set to meet peak load, saving energy and protecting the environment. The function is shown in Figure 2.

\subsection{Short-term energy supply}

The parallel operation mode and the island operation mode are two typical operation modes of the micro power grid. Under normal circumstances, the traditional distribution network and micro power grid operate parallelly. Once power quality problems and power grid failure are detected, micro power grid will disconnect with power grid immediately and then work independently. In the process of these two kinds of mode conversion, there will always be some power defects of the micro-grid, and we can guarantee the smooth transition of the two models by installing certain energy storage device to store energy in the system ensuring that it can guarantee system stability. In the process of new energy power generation, energy cannot be often normal outputted (no light, no wind, etc.) because of external conditions. In this case, the continue usage of power storage system can provide power for users.

\subsection{Improve the quality of power}

In recent years, power quality problems have received more and more attention, and many researchers have carried out extensive research at both China and abroad. As an external micro source, when micro power grid is put on parallel operation with large power grid together, it must meet the requirements of the power factor, current harmonic distortion rate,

*Corresponding author: 2976273238@,qq.com

This is an Open Access article distributed under the terms of the Creative Commons Attribution License 4.0, which permits unrestricted use, distribution, and reproduction in any medium, provided the original work is properly cited. 


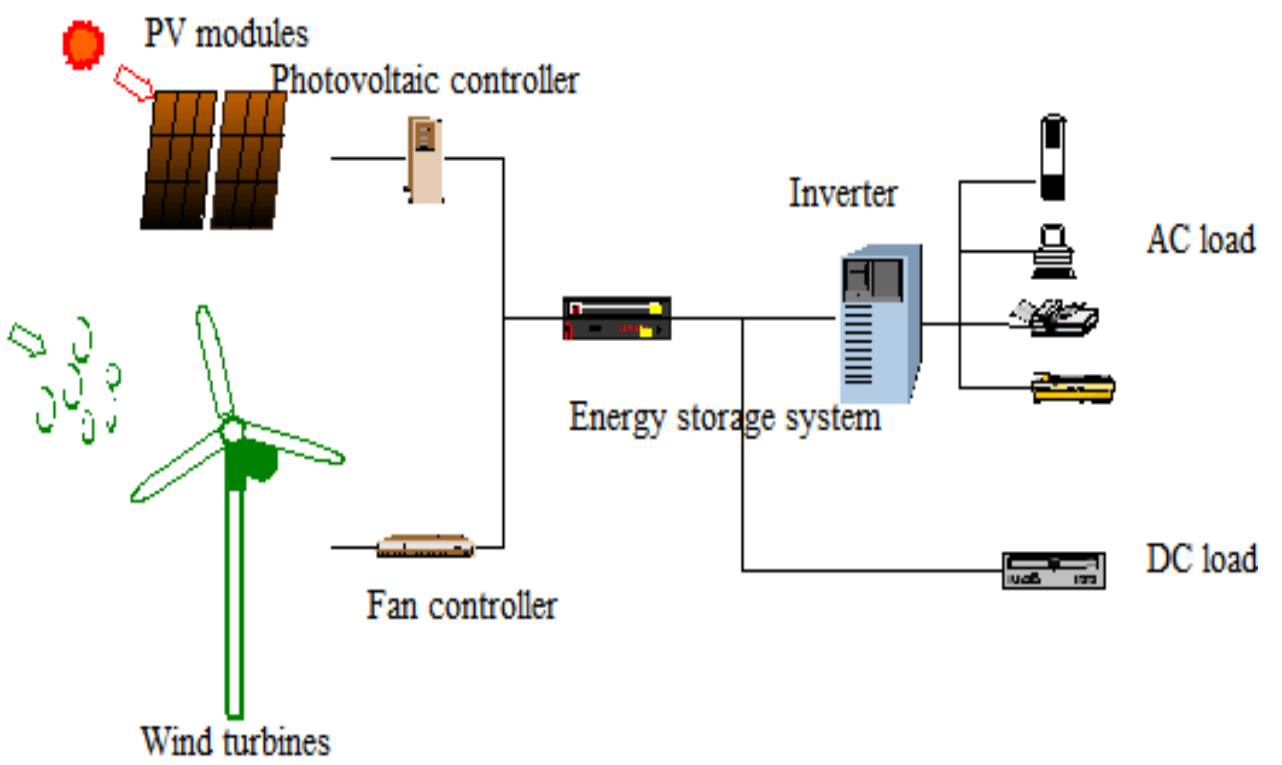

Figure 1. The application of energy storage technology in micro-grid

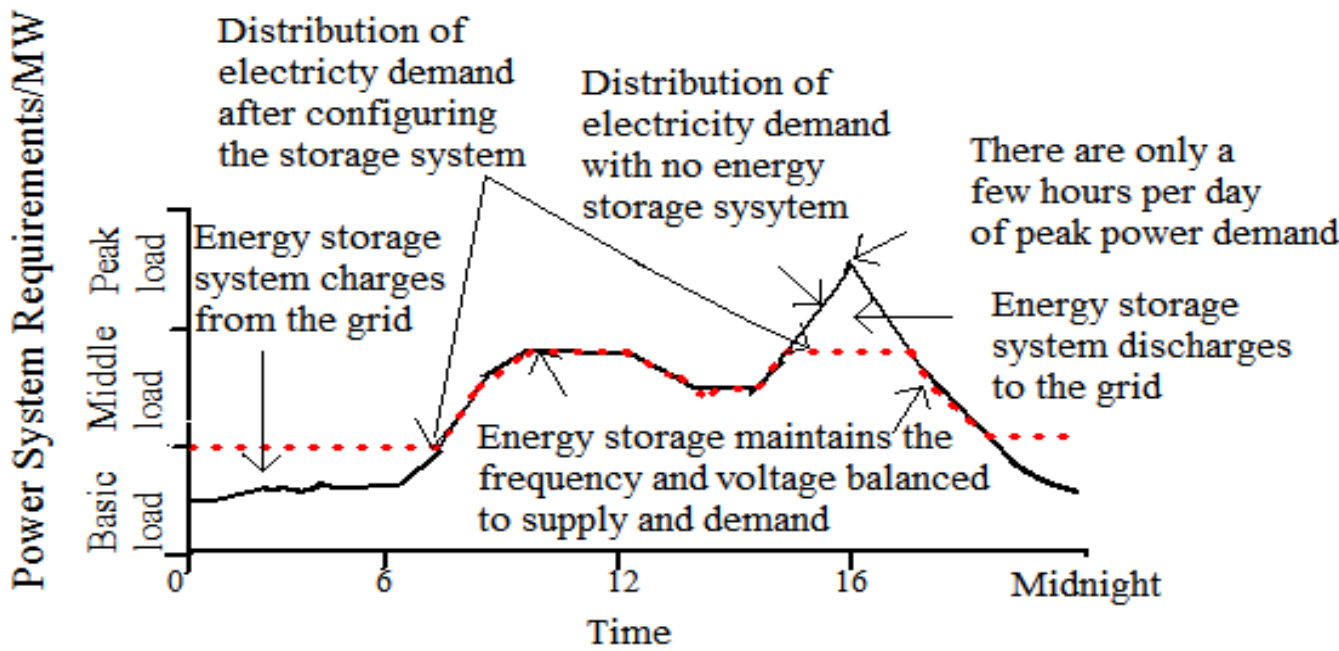

Figure 2. The renderings in load shifting of energy storage technology

voltage flicker and asymmetric voltage. In addition, the influence of grid power quality for its load is also an important problem, with which the micro-grid must consider to ensure that the power supply voltage, frequency and power frequency are in a small range. On improving micro-grid power quality, energy storage system plays a very important role by controlling the inverter to provide active power and reactive power to the power grid and load, eventually improving the quality of electric energy.

With the change of the solar and wind power external condition, the output power will change, which results a decline in the power quality. Taking into account the power quality problems such as voltage sag, voltage drop, the combination the micro power with the energy storage device can well solve these conditions above. For the instantaneous power failure, voltage surge, voltage sag and other problems caused by fault, energy storage devices can be used to provide rapid power buffer, absorb or supply power, generate active power compensation and reactive power compensation, and ultimately achieve stable and smooth power grid voltage fluctuation. Figure 3 expounded that energy storage device could be joined to improve the transient voltage stability ${ }^{[3]}$. 


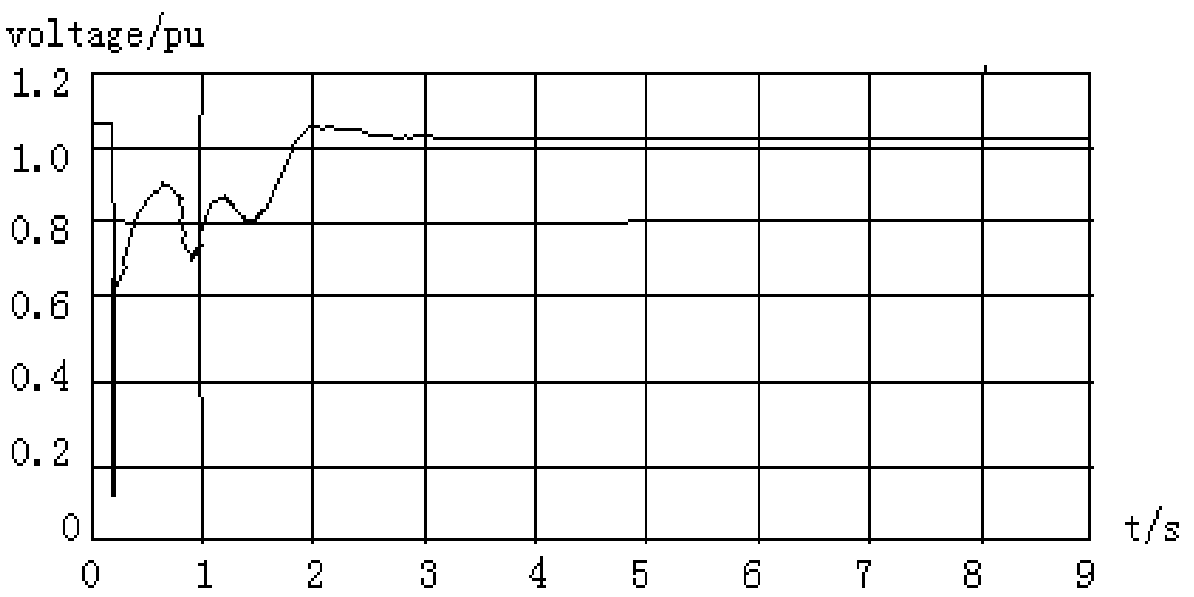

Figure 3. The stability improvement of the transient voltage by energy storage device

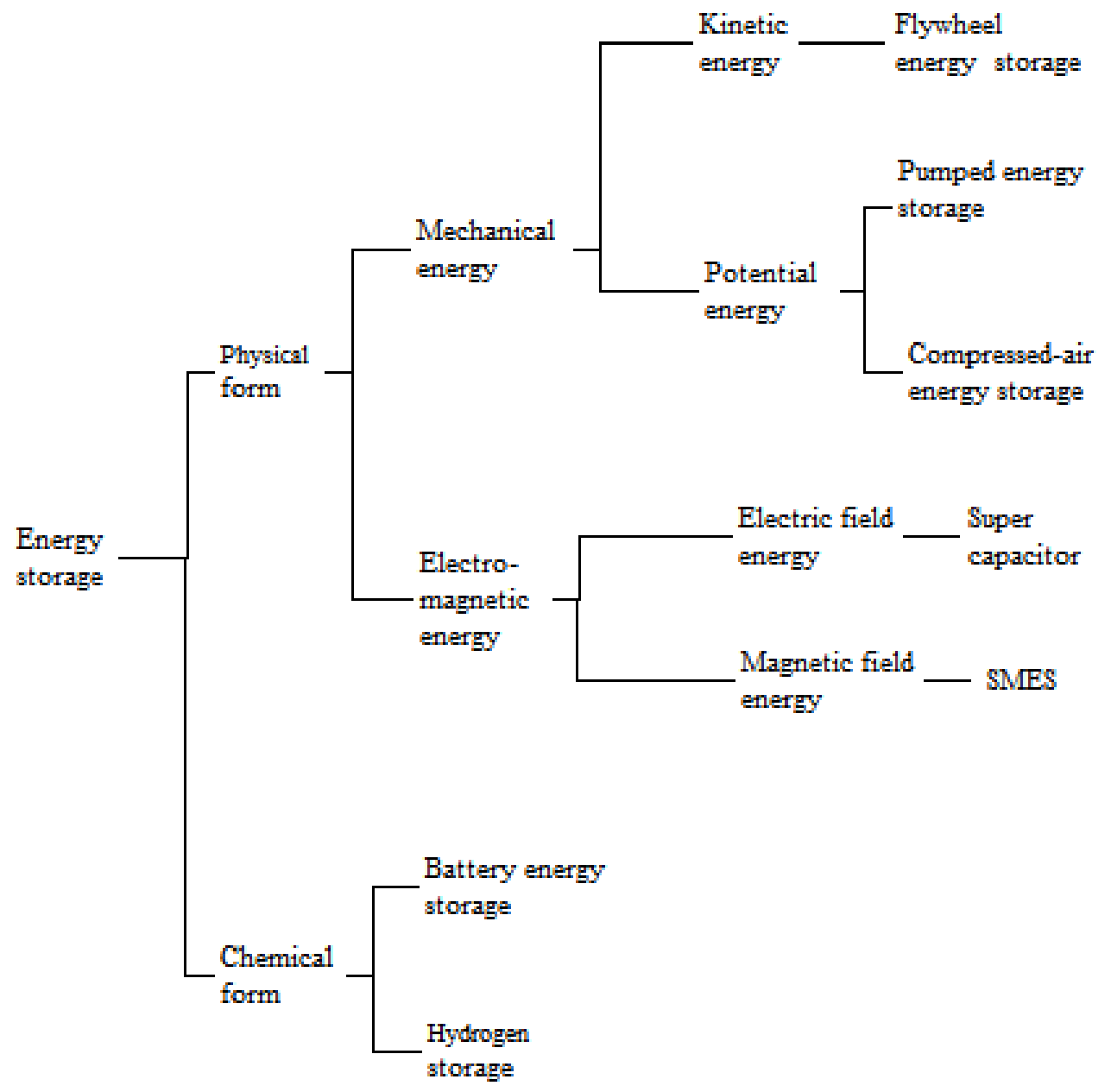

Figure 4. Classification of electrical energy storage 
MATEC Web of Conferences

Table 1. Comparison of some energy storage technologies in electric power system

\begin{tabular}{|c|c|c|c|}
\hline Type & Advantage & Disadvantage & Application \\
\hline Pumped storage & $\begin{array}{l}\text { can be massive, } \\
\text { nature technology }\end{array}$ & $\begin{array}{l}\text { limited location, } \\
\text { large investment } \\
\text { project }\end{array}$ & $\begin{array}{l}\text { system backup, } \\
\text { frequency control, }\end{array}$ \\
\hline $\begin{array}{l}\text { Flywheel energy } \\
\text { storage }\end{array}$ & $\begin{array}{l}\text { fast response, } \\
\text { instantaneous } \\
\text { power, } \\
\text { fast response, } \\
\text { environmental } \\
\text { pollution }\end{array}$ & $\begin{array}{l}\text { low energy density, } \\
\text { high cost to ensure the safety of the } \\
\text { system, } \\
\text { big noise }\end{array}$ & $\begin{array}{l}\text { frequency control, } \\
\text { UPS, } \\
\text { power quality, } \\
\text { peak shaving }\end{array}$ \\
\hline Flow battery & $\begin{array}{l}\text { long life, } \\
\text { easy combination, } \\
\text { high efficiency, }\end{array}$ & small battery capacity & $\begin{array}{l}\text { reliability control, } \\
\text { backup power, } \\
\text { renewable energy, } \\
\text { power quality }\end{array}$ \\
\hline Lithium-ion battery & $\begin{array}{l}\text { light weight, } \\
\text { large storage } \\
\text { capacity, } \\
\text { small self- } \\
\text { discharge } \\
\text { coefficient }\end{array}$ & $\begin{array}{l}\text { high cost, } \\
\text { immature large-scale m- } \\
\text { ass production }\end{array}$ & $\begin{array}{l}\text { power quality, } \\
\text { reliability control, } \\
\text { backup power, } \\
\text { renewable energy }\end{array}$ \\
\hline SMES & $\begin{array}{l}\text { fast response, } \\
\text { high conversion } \\
\text { efficiency, } \\
\text { big specific } \\
\text { power }\end{array}$ & $\begin{array}{l}\text { high cost, } \\
\text { difficult maintenance }\end{array}$ & $\begin{array}{l}\text { voltage support, } \\
\text { power compensation, } \\
\text { system stability } \\
\text { improvement }\end{array}$ \\
\hline Super- capacitors & $\begin{array}{l}\text { simple installation and } \\
\text { run in a variety of envi- } \\
\text { ronments }\end{array}$ & $\begin{array}{l}\text { high cost, } \\
\text { low energy storage }\end{array}$ & $\begin{array}{l}\text { short-term, high-power } \\
\text { load smoothness }\end{array}$ \\
\hline
\end{tabular}

2.4 Improve the performance of the power supply in micro power grid

Renewable energy such as solar energy, wind energy, tidal energy has the inhomogeneity and the uncontrollability, and the output of electricity is likely to change at any time. As light, temperature, wind and other factors in the environment change, the corresponding output of micro energy will also change. Energy storage link in the system can be used to store energy for better solving such problems. For example, in the night, in the place with no wind or during the maintenance of other micro power supplies, the system of energy storage can be more helpful and the load demand plays a main role in deciding the capacity of energy storage.

\section{COMPARISON OF VARIOUS ENERGY STORAGE METHODS}

The characteristics and working principles of micro power grid have relatively unique requirements for the performance characteristics of energy storage device. To sum up, the requirements are: the big energy density, the small size of weight which can provide great- er energy, high power density, fast response, the capacity of providing compensatory power for system when mutations occurred, high source storage efficiency, good high and low temperature performance that can run reasonably in some special environment. Developed up to now, there has been a lot of micro-grid energy storage equipment used in the actual production, including battery energy storage, SMES, flywheel energy storage, super capacitor storage, etc. According to the form of energy storage, storage ways can be roughly divided into physical energy storage and chemical energy storage. And the physical energy storage can be divided into mechanical energy storage and electromagnetic field energy storage, as shown in the Figure 4.

The performance comparison of some energy storage technologies is shown in the Table 1.

\subsection{Battery energy storage}

Battery energy storage system can meet the demand of electricity in the load peak of system, assist reactive power compensation device, and suppress the voltage fluctuation and flicker simultaneously. Depending on the use of chemical substances, battery energy storage can be divided into the following several ways: 


\subsubsection{Lithium ion batteries}

As a new battery, lithium ion battery belongs to the new type high-energy secondary battery, initiated by the Japanese electronics giant SONY corp. in 1992. It has characteristics of high voltage, small size, high energy storage density, environmental protection, and long cycle life. But its special packaging of overcharge protection circuit causes the high production cost, which eventually makes the mass production difficult.

\subsubsection{Lead-acid battery}

Although there are many shortcomings of lead-acid battery, it can be mainly used for commercial, and it has significant advantages which are low cost, abundant raw materials, and mature production technology, which can be mass-produced. But the characteristics of large lead-acid battery can be significantly affected by environmental temperature.

\subsubsection{Liquid metal batterie}

Liquid metal batteries are developed by the liquid electrolytic cell; the battery uses molten metal as the positive and negative of battery, because the molten salt electrolyte does not mutually mix with molten metal, which leads to the formation of a liquid layer because of the difference of the density stratification. The charge and discharge is a reciprocal process. In the process of discharge, the cathode metal acts in the external circuit by losing electronic power, and then the cathode metal makes ionization, arrives at the positive pole of the battery through the electrolyte, and alloys with the positive metal.

The special design of liquid metal batteries can overcome the slow dynamics characteristic of solid electrode of the traditional battery, and inorganic molten salt with high conductivity also greatly increases the rate of the electrolyte ion migration. This can ensure that the charging and discharging energy efficiency is still high when the current density is low. Due to long-term usage, the electrode can deform and have dendrite growth, and thus it can affect battery life and security. But these factors do not exist in liquid electrode. So it has the advantages of long service life and high safety performance. Inorganic molten salt can not only act as electrolyte, but also act as positive and negative poles on both sides of the isolation layer. It makes the liquid metal batteries have no special battery diaphragm. This special structure will reduce the production cost and improve the scalability of the system. But simultaneously, the liquid metal batteries also has problems such as high temperature sealing and corrosion technology defects.

\subsection{Pumped energy storage}

Pumped energy storage has been widely applied. The basic principle of pumped energy storage is using excess electric after midnight to drive pumps to draw water from the down reservoir to the up reservoir for storage, then in the next day release the water for power generation, and the water flows into the down reservoir. The advantages of pumped energy storage are mature technology, low cost, and circulating water use. While the defects are the construction of pumped storage which needs special geographical conditions. The large pumping stations are usually in the mountains far away from the wind farm. The increase of the distance means that the increase of the transmission loss. The efficiency of pumped energy storage is only $70 \%$ and its construction time is about 8 to 10 years. In recent years, six pumped storage power stations in operation are shown in the Table 2.

\begin{tabular}{|c|c|c|c|}
\hline $\begin{array}{l}\text { Power sta- } \\
\text { tion }\end{array}$ & Countries & $\begin{array}{l}\text { The installed } \\
\text { capaci- } \\
\text { ty/MW }\end{array}$ & $\begin{array}{l}\text { Years of } \\
\text { construction }\end{array}$ \\
\hline $\begin{array}{l}\text { The Rocky } \\
\text { Mountains }\end{array}$ & America & 760 & 1995 \\
\hline Okukiyotsu & Japan & 600 & 1996 \\
\hline $\begin{array}{l}\text { Kazuno- } \\
\text { gawa }\end{array}$ & Japan & 1600 & 1999 \\
\hline Kaneya & Germany & 1060 & 2003 \\
\hline $\begin{array}{l}\text { Kanna- } \\
\text { gawa }\end{array}$ & Japan & 2820 & 2005 \\
\hline $\begin{array}{l}\text { Omaru- } \\
\text { gawa }\end{array}$ & Japan & 1200 & 2007 \\
\hline
\end{tabular}

\subsection{Compressed-air energy storage}

Compressed-air energy storage means the way of energy storage that uses electricity to compress air in the trough of power load, and then pressurizes air in the discarded mine, the storage tanks made settlement of underwater, the caves, expired oil and gas wells or a new gas storage well. While in the peak of power load it releases the compressed air to drive steam turbine to generate power energy. At present, the forms of compressed air energy storage system are also varied. According to the working medium, storage medium and heat source, it can be divided into three sorts: traditional compressed air energy storage system (which needs the burning of fossil fuels), a kind of compressed air energy storage system with thermal storage device, and liquid-gas compressed energy storage system. Due to the mature technology and larger scale development, compressed-air energy storage's cost is very low, and it is one of the lowest cost ways. It has the characteristics of long life, slower response time than battery, capacitance, flywheel energy storage, and great capacity, etc. Compressed-air energy storage is suitable for large-scale wind field, because they have the advantage of the natural combination: the mechanical energy produced by wind power can directly drive compressor rotation, which reduces the intermediate links of converting to electricity, improving efficiency. 


\subsection{Flywheel energy storage}

It belongs to the mechanical energy storage. Advantages of flywheel energy storage are fairly obvious: high efficiency, short construction period, long service life, high energy storage, quick charging, infinite time of charging and discharging simultaneously, and environmental protection. However, the disadvantage is that the cost of maintenance is much larger. There has been a lot of research for its application on micro power grid at home and abroad now. For example, the combination of the static reactive power compensator and flywheel energy storage system was applied to reducing the power quality problems caused by the wind $^{[4]}$.

\subsection{SMES}

SMES is made of superconducting coil. Compared with other energy storage technology, its long-term storage has no energy loss, so the small and medium-sized enterprises can obtain more benefits from high energy efficiency and high energy release rate. It can also be easier to adjust the grid voltage, frequency, active and reactive power. However, the price of superconductors is too high which leads to a too large one-off investment. The rapid development of HTS and power electronic technology promotes the application of superconducting energy storage device in power system. In the 1990 s, wind power and photovoltaic power generation had extensive use of the technology. Rapid throughput of power and four quadrants' flexible adjustment make it effective for tracking electric parameters fluctuation and improving system damping. Superconducting energy storage system is beneficial to increasing the running stability of pv system, improving the rate of absorption and release of the active and reactive power.

\subsection{Super capacitor energy storage}

Super capacitors have high power density, long charge-discharge cycle life, high charge-discharge efficiency, relatively fast charging and discharging rate, good high and low temperature performance, long storage life, and so on. Compared with the flywheel energy storage, it has no moving parts, less maintenance, very high reliability and other advantages. These features make it have certain advantages when it is applied to micro power grid. As the new energy, solar energy and wind power is the most convenient energy. As the energy storage system of these two kinds of electricity, battery has the weaknesses of short service life and pollution, superconducting energy storage and flywheel energy storage's cost is too high, so super capacitor becomes more ideal energy storage device. With the development and matureness of technology, the super capacitor has already been applied in power supply such as mountain observatory, border posts. But simultane- ously, we can also see that the super capacitor has many disadvantages: low energy density, large voltage fluctuation range, series capacity balance problems, etc.

\subsection{Hydrogen storage}

Hydrogen storage means when at the time of power supply exceeds demand, use the method of water electrolysis technology to get hydrogen, and then store it in the state of liquid at low temperature by combustion to produce energy, which is required. Water electrolysis technology is the most flexible option which is used to solve large-scale storage and continuous renewable energy problems. At present, the setback of this technology is how to expand the scale of the hydrogen generator to meet the growing demand for renewable energy electricity industry. The biggest advantage of hydrogen storage is extensibility. A $2 \mathrm{MW}$ hydrogen cell can be used as a bearer of energy storage, and it's conveniently installed in both the distribution substations and the wind turbines. Now Proton OnSite company manufacturing factory already has a lot of prototype model in the level of MW, which is being tested. And the strategy of hydrogen energy storage applied to renewable energy grid has been launched in Germany.

\section{DEVELOPMENT TREND OF ENERGY STORAGE TECHNOLOGY GEARED TO MI- CRO-GRID}

To sum up, all kinds of energy storage methods cannot take into account safety, high power, high energy, long service life, mature technology and wide working temperature range, but micro-grid energy storage technology still has profound research prospect and development space.

(1) Innovative low-cost, high efficiency, charging and discharging speed method of energy storage battery: the high cost of energy storage technology is the bottleneck of large-scale promotion now, therefore, improving the efficiency and the rate is also a good way to solve the problem.

(2) The hybrid energy storage technology: all kinds of energy storage methods have limitations. Making the best of their advantages and taking the hybrid energy storage technology can significantly improve the performance of the system.

(3) The analysis theory and method of energy storage system applied in the micro-grid: fully understand the dynamic characteristics of micro power grid contained energy storage device, on the basis of it, research the complex nonlinear electromagnetic problems inside the energy storage device, as well as the interaction between energy storage devices with the components in the system.

(4) To realize energy management theory and methods of energy storage device under the market condition: the owner of a micro power grid energy storage device must retain real-time network infor- 
mation, including electricity price and power grid failure, etc. Only in this way, can we make full use of the micro-grid energy storage device.

\section{CONCLUSION}

As the scale of power grid in China is bigger and bigger, the power system's shortcomings are more outstanding. The micro-grid can disperse power load and improve the reliability of power grid. The energy storage technology can significantly improve the micro-grid power quality. Therefore, it will have a broad space for development.

\section{ACKNOWLEDGEMENT}

This work was supported by Shanghai Municipal Natural Science Foundation (No. 14ZR1417200, No.15ZR1417300, No.12ZR1411600), Innovation Program of Shanghai Municipal Education Commission (No. 14YZ157, No. 15ZZ106). Shanghai science and technology program(2014MH166).

\section{REFERENCES}

[1] Cheng Shijie. Wen Jingyu. \& Sun Haishun. 2005. Energy storage technology and its application in modern power system. Electrical Applications, 24(4): 1-8.

[2] Jiang Kai. Li Haomiao. Li Wei. \& Cheng Shijie. 2013. A few class for grid energy storage battery is introduced. Electric Power System and its Automation, 37(1): 47-53.

[3] Chen Jianbin. Hu Yufeng. \& Wu Xiaochen. 2010. The application prospect of analysis of energy storage technology in the southern power grid. Southern Power Grid Technology, 4(6): 32-36.

[4] Deng Zigang, Wang Jiasu. \& Wang Suyu. 2008. The current situation of the development of high temperature superconducting flywheel energy storage technology. Journal of Electrotechnics, 23(12): 1-10.

[5] Ausfelder Florian, Beilmann Christian, Bertau Martin. \& Bruninger Sigmar. 2015. Energy storage technologies as options to a secure energy supply. Chemie Ingenieur Technik, 87(2): 17-89.

[6] Gude, Veera Gnaneswar. 2015. Energy storage for desalination processes powered by renewable energy and waste heat sources. Applied Energy, 137(1): 877-898.

[7] Xiaojuan Han, Tianming Ji, Zekun Zhao. \& Hao Zhang. 2015. Economic evaluation of batteries planning in energy storage power stations for load shifting. Renewable Energy, 78(6): 643-647.

[8] Kailasan Arunvel, Dimond Timothy, Allaire Paul. \& Sheffler David. 2014. Design and analysis of a unique flywheel energy storage system - An integrated flywheel, Motor/Generator and magnetic bearing configuration. Proceedings of the ASME Turbo Expo.

[9] Cho Jaephil, Jeong Sookyung. \& Kim Youngsik. 2015 Commercial and research battery technologies for elec- trical energy storage applications. Progress in Energy and Combustion Science, 48(6): 84-101.

[10]Raza Syed Shabbar, Janajreh Isam. \& Ghenai Chaouki. 2014. Sustainability index approach as a selection criteria for energy storage system of an intermittent renewable energy source. Applied Energy, 136(12): 909-920.

[11]Misao Kimura, Hideki Hayashi, Toshiyuki Kajihara, Masakazu Kato. \& Katsuhiko Kouchi. 2008. Power System Control Method Using Customers' Energy Storage Systems and the Verification of Proposed Method. Electrical Engineering in Japan, 165(4): 451-458.

[12]Li Yongliang, Y. Jin, Chen Haisheng, Tan Chunqing. \& DingYulong. 2011. An integrated system for thermal power generation, electrical energy storage and $\mathrm{CO} 2$ capture. International Journal of Energy Research, 35(13): 1158-1167.

[13]Guo wei, Wang Yue. \& Li Ning. 2014. Charge and discharge control for the flywheel energy storage system of permanent magnet synchronous motor. Journal of Xi'an Jiaotong University, 48(10): 1-7.

[14]GE Jusheng, WANG Peihong. 2012. New type of flywheel energy storage technology and its forecast of application. Power and Energy, 33(2): 181-184.

[15]Zhang Buhan, Chen Yi, Dai Xiaokuang. \& Zhao Shuang. 2014. Micro network in distributed storage system control parameter optimization methods. Journal of Hua Zhong University of Science and Technology, 42(12): $1-5$.

[16] Wu Zhonghua. 2014. Application of battery energy storage technology in the grid network of the renewable energy power plants. Journal of Nantong Vocational University. 28(2): 93-98.

[17]Diaz-Gonzaleza F, Sumpera A. \& Gomis-Bcllmunt O, et al. 2012. A review of energy storage technologies for wind power applications. Renewable and Sustainable Energy Reviews, 16(4): 2154-2171.

[18]Tang Wenzuo, Liang Wenju, Cui Rong, Zeng Rui, Ja Long, Zhou Chuanjie. \& Hu Zechun. 2015. Optimal allocation method of distributed energy storage system in distribution network. Electric Power Construction 36(4): 38-45.

[19]Dong Litong, Xu Jun. \& Liu Haibo. 2012. Application and analysis of DSM and energy storage technology for industrial peak load management. Electric Power, 45(4): 47-50.

[20]Jin Yiding, Song Qiang. \& Chen Jinhui, et al. 2010. Power conversion system of large scaled battery energy storage. Electric Power, 43(2): 16-20.

[21] Wu Wenxuan. 2012. The optimal placement of different types of distributed generation in distribution network. Modern Electric Power, 29(3): 6-11.

[22]Xiang Ping, Zhou Shaofeng. \& Zhang Lei. 2013. Study on a PV battery hybrid with supercapacitor and energy storage. Northwestern Polytechnical University.

[23]Xian Kai. \& Xu Changkui. 2015. Research on the method based on hybrid energy storage system for balancing wind power. Applied Science and Technology, 42(2): $1-5$ 
MATEC Web of Conferences

[24] Jin Hong. \& Yi Jin. 2012. Market and economic analysis of the energy storage industry. Energy Storage Science and Technology, 1(2): 103-111.

[25]Liu Shinian, Su Wei. \& Wei Zengfu. 2013. Application effect evaluation of the chemical energy storage battery in electric power system. Renewable Energy Resources, 31(1): 105-108. 